\title{
Midterm follow-up of the reimplantation technique in patients with relatively normal annulus: Is David I still a clinically valid option?
}

\author{
Carmelo Mignosa, MD, Salvatore Di Stefano, MD, Massimo Mazzamuto, MD, Nello Degno, MD, \\ Carlo Mariani, MD, Antonella Romeo, MD, and Antonino S. Rubino, MD
}

\begin{abstract}
Objective: The aim of this study was to evaluate the midterm results of the reimplantation technique with a straight tubular graft in patients with aortic root aneurysms with or without aortic insufficiency.
\end{abstract}

\begin{abstract}
Methods: From February 2002 to November 2012, 51 consecutive patients underwent the David I valve-sparing aortic procedure for aortic root aneurysm; the mean age was $59.9 \pm 12.3$ years. Nine patients $(17.6 \%)$ had a bicuspid aortic valve. Patients were followed prospectively for $4.78 \pm 3.60$ years (median, 5 years). Operative results, survival, freedom from redo aortic surgery and from recurrent aortic insufficiency greater than $2+$ were assessed.
\end{abstract}

\begin{abstract}
Results: No in-hospital mortality was recorded. In 5 cases, adjunctive procedures on the aortic valve were needed to achieve good leaflet coaptation. Aortic regurgitation was significantly lower at discharge $(2.3 \pm$ 1.0 vs $0.3 \pm 0.5 ; P<.001)$. There were 5 postoperative deaths, all noncardiac related. Survival was $91.0 \% \pm$ $4.4 \%$ at 5 years; freedom from redo aortic surgery was $96.8 \% \pm 3.2 \%$ and freedom from recurrent aortic insufficiency greater than $2+$ was $96.8 \% \pm 3.2 \%$. The outcomes in patients with repaired bicuspid aortic valves showed no significant differences compared to the outcomes in patients with repaired tricuspid valves.
\end{abstract}

Conclusions: The reimplantation procedure using a straight tube is a safe and reproducible valve-sparing technique that can achieve no in-hospital mortality and durable midterm results, either in bicuspid or tricuspid valves. Further studies are needed to assess the behavior of repaired valves under physical stress at long-term follow-up. (J Thorac Cardiovasc Surg 2014;148:1334-40)

Since David and Feindel ${ }^{1}$ and Sarsam and Yacoub ${ }^{2}$ first described techniques to preserve the aortic valve during aortic root replacement, valve-sparing procedures have gained widespread acceptance and have stimulated research on the physiopathology of aortic valve insufficiency.

It is general knowledge that the reimplantation technique addressing dilation of the aortic root, both at the level of the aorto-ventricular junction and sino-tubular junction, guarantees better stabilization of the functional aortic annulus. ${ }^{3}$ However, the debate about which of the techniques is superior to the other to guarantee an optimal performance of the aortic valve is still under debate. In particular, since Bellhouse $^{4}$ and Thubrikar and colleagues ${ }^{5}$ confirmed the role of the sinuses of Valsalva on the opening and closing mechanisms of the aortic valve, the original technique, the socalled David I technique, ${ }^{6}$ was implemented to recreate as

From the Cardiac Surgery Unit, A.O.U. "Policlinico-Vittorio Emanuele," Ferrarotto Hospital, University of Catania, Catania, Italy.

Disclosures: Authors have nothing to disclose with regard to commercial support. Received for publication Sept 3, 2013; revisions received Nov 18, 2013; accepted for publication Nov 29, 2013; available ahead of print Feb 8, 2014.

Address for reprints: Antonino S. Rubino, MD, Cardiac Surgery Unit, A.O.U. "Policlinico-Vittorio Emanuele," Ferrarotto Hospital, University of Catania, Via Citelli, 95124 Catania, Italy (E-mail: antonio.rubino@hotmail.com).

$0022-5223 / \$ 36.00$

Copyright (c) 2014 by The American Association for Thoracic Surgery

http://dx.doi.org/10.1016/j.jtcvs.2013.11.042 much as possible the presence of neosinuses until a new tubular prosthesis with sinuses already included in the graft was developed.

However, although better motion of the aortic leaflet has been demonstrated in the presence of neosinuses, the clinical superiority of the newly described reimplantation techniques over the original David I techniques has never been proved. ${ }^{8}$

Therefore, it was the aim of this study to evaluate the midterm clinical results of a consecutive series of patients undergoing valve-sparing aortic root replacement with the reimplantation technique using a straight tube at a single institution.

\section{PATIENTS AND METHODS \\ Patient Profile}

Data from 51 consecutive patients who underwent valve-sparing aortic root replacement with the reimplantation technique from December 2002 to November 2012 were retrospectively collected.

The indication for surgery was an aortic root aneurism with or without aortic insufficiency. The mechanism of aortic regurgitation was classified according to Boodwani and colleagues. ${ }^{9}$

The morphology of the aortic valve was described according to Sievers and Schmidtke, ${ }^{10}$ implemented with the functional classification proposed by Boodwani and colleagues ${ }^{11}$ for the bicuspid aortic valve.

Exclusion criteria were age greater than 70 years (only in cases of remodeled aortic cusps), aortic valve stenosis, severe calcification of at least 1 cusp (eg, insufficiency type III or Ib in the case of the bicuspid valve), prolapse of all the cusps, need for more than 2 repair procedures apart from the David technique. 


\section{Abbreviation and Acronym \\ $\mathrm{CTA}=$ computed tomography angiography}

All patients underwent preoperative transthoracic echocardiography and computed tomography angiography (CTA) of the thoracic aorta. Coronary angiography was required unless patients were less than 40 year old and had no risk factors for ischemic heart disease.

Institutional review board approval for the study protocol was obtained.

\section{Surgical Technique}

The surgical technique was standardized and did not change during the study period. All procedures were performed using a single straight tubular Dacron graft. In all patients, surgery was performed through a median sternotomy or reversed-Y mini-sternotomy by the same experienced surgeon (C.M.).

After aortic crossclamping, the ascending aorta is transected at the level of the sino-tubular junction, removing the dilated aortic wall. The commissures are suspended on $4 / 0$ polypropylene stay sutures and the aortic valve is inspected. If the valve anatomy is suitable for sparing, the aortic root is dissected as close to the annulus as possible, below the nadir of the cusps. The sinuses of Valsalva are excised, leaving a 3 to $5 \mathrm{~mm}$ remnant of the aortic wall for subsequent reimplantation. The coronary buttons are isolated. The stay sutures are gently pulled up until good leaflet coaptation is reached. At this time, the diameter of the graft is chosen by measuring the distance from a commissure to the insertion of the opposite leaflet, then approximating to the next largest size (eg, if $29 \mathrm{~mm}$ is measured, we choose a $30-\mathrm{mm}$ graft).

Then, U stitches (usually 12) of 2/0 coated polyester fiber with Teflon pledgets are placed circumferentially, inside out and horizontally, below the nadir of the leaflets in the left ventricular outflow tract and are used to anchor the Dacron graft, which had been previously incised for a 2 to 3 $\mathrm{mm}$ length to correspond with the nadir of each commissure, to shape the prosthetic edge in a scalloped way to correspond with the scalloped native annulus. In this way, the prosthetic edge is positioned slightly below the level of the annulus. Thereafter, the commissures are pulled up inside the graft and fixed at the desired level with 3 running 4/0 polypropylene sutures.

When the valve has been completely reimplanted inside the graft, saline is injected to test the competence of the valve. If necessary, adjunctive repair techniques are used according to the cause of the coaptation defect, ${ }^{12}$ The coronary ostia are reimplanted with the button technique with 2 running $5 / 0$ polypropylene sutures. Cardioplegia is then applied directly inside the graft to test the competence of the valve and to check for adequate hemostasis.

According to our institutional protocol, distal anastomosis is performed with the open technique, under mild hypothermic circulatory arrest (28$30^{\circ} \mathrm{C}$ ) and retrograde cerebral perfusion through the superior vena cava. Antegrade selective cerebral perfusion is used only when the arch and/or the descending aorta is involved. Distal anastomosis is performed during aortic crossclamping only when the ascending aorta is not dilated and the aortic valve is tricuspid.

Transesophageal echocardiographic control is performed after discontinuation of cardiopulmonary bypass. ${ }^{13}$ The evidence of residual aortic insufficiency of 2 or more indicates the need to reexplore the valve. If good coaptation is achievable, an adjunctive repair technique is performed; otherwise, the aortic valve is replaced with a prosthesis. This was required in 2 cases: in 1 case, an adjunctive resuspension of the free margin was required; in the other case, the aortic valve was replaced with a biological prosthesis and, therefore, this patient was not included in the study.

\section{Study Design and End Points}

Clinical follow-up took place in our outpatient clinic. Primary end points were survival at follow-up, freedom from reoperation on the aortic valve, and freedom from recurrent aortic insufficiency greater than $2+$. Valve motility was assessed on 128-slice CTA in a subset of patients with the longest follow-up.

Hospital outcomes (in-hospital mortality and grade of aortic insufficiency at discharge) were also recorded.

\section{Statistical Analysis}

Statistical analysis was performed using the SPSS program for Windows, version 15.0 (SPSS, Inc, Chicago, Ill). Continuous variables are presented as means \pm standard deviation, and categorical variables are presented as absolute numbers and/or percentages. Freedom from timerelated events was investigated using Kaplan-Meier analysis. Subgroup comparisons between patients with tricuspid aortic valves and bicuspid aortic valves were performed using the log-rank test.

\section{RESULTS}

Preoperative characteristics are described in Tables 1 and 2. Nine patients $(17.9 \%)$ had a bicuspid aortic valve. In all 9 cases, it was classified as type I according to Sievers and Schmidtke ${ }^{10}$ or type Ia according to Boodhwani and colleagues. ${ }^{11}$ Two patients $(3.9 \%)$ had a genetic diagnosis of Marfan syndrome.

\section{Operative Details}

A straight tubular Dacron graft was used to replace the aortic root in all cases. The mean graft diameter was 29.2 $\pm 1.2 \mathrm{~mm}$ (range, $26-32 \mathrm{~mm}$ ).

In 5 patients $(9.8 \%), 1$ or more adjunctive repair techniques were used to achieve good leaflet coaptation; in particular, shaving 3 times $(5.9 \%), 2$ subcommissural annuloplasty $(3.9 \%), 1$ free margin plication $(2.0 \%), 1$ free margin resuspension and reinforcement with a $6 / 0$ polytetrafluoroethylene (Gore-Tex; W. L. Gore \& Associates, Inc, Flagstaff, Ariz) over-and-over running suture $(2.0 \%)$, and 1 patch enlargement $(2.0 \%)$.

An open distal anastomosis, with retrograde cerebral perfusion, was performed in 49 patients $(96.1 \%)$. The mean circulatory arrest time was $10.3 \pm 1.8$ minutes.

\section{Hospital Outcomes}

No in-hospital mortality or transient neurologic deficit was recorded.

At transthoracic echography performed at hospital discharge, only 1 patient showed aortic insufficiency greater than $2(2.0 \%)$. Compared with the preoperative records, a significant reduction in the grade of aortic insufficiency was observed at discharge $(2.3 \pm 1.0$ vs $0.3 \pm 0.5$; $P<.001$ ) (Figure 1).

\section{Follow-up}

Follow-up was $100 \%$ complete. Mean follow-up duration was $4.75 \pm 3.60$ years (range, 0.9-10 years; median, 5 years), accounting for a total of 242 patient-years (Table 3 ).

Five patients died during follow-up, giving a cumulative survival at 5 years of $91.0 \% \pm 4.4 \%$ (Figure 2). 
TABLE 1. Preoperative variables $(\mathbf{n}=\mathbf{5 1})$

\begin{tabular}{lc}
\hline \multicolumn{1}{c}{ Variable } & Preoperative value \\
\hline Age, $\mathrm{y} \pm \mathrm{SD}$ & $59.9 \pm 12.3$ \\
Male gender, $\mathrm{n}(\%)$ & $44(86.3)$ \\
Height, $\mathrm{m} \pm \mathrm{SD}$ & $170.0 \pm 6.6$ \\
Weight, $\mathrm{kg} \pm \mathrm{SD}$ & $77.4 \pm 10.3$ \\
Body surface area, $\mathrm{m}^{2} \pm \mathrm{SD}$ & $1.91 \pm 0.15$ \\
Body mass index, kg/m ${ }^{2} \pm \mathrm{SD}$ & $26.8 \pm 3.3$ \\
Systemic arterial hypertension, $\mathrm{n}(\%)$ & $37(72.5)$ \\
Chronic renal insufficiency, $\mathrm{n}(\%)$ & $5(9.8)$ \\
Peripheral vascular disease, $\mathrm{n}(\%)$ & $1(2.0)$ \\
Chronic obstructive pulmonary disease, $\mathrm{n}(\%)$ & $6(11.8)$ \\
Insulin-dependent diabetes mellitus & $1(2.0 \%)$ \\
New York Heart Association class III-IV, $\mathrm{n}(\%)$ & $32(62.7)$ \\
Acute myocardial infarction, $\mathrm{n}(\%)$ & $1(2.0)$ \\
Previous cerebrovascular accident, $\mathrm{n}(\%)$ & $2(3.9)$ \\
Urgent surgery, $\mathrm{n}(\%)$ & $5(9.8)$ \\
Mitral regurgitation, $\mathrm{n}(\%)$ & $2(3.9)$ \\
Chronic ischemic cardiomyopathy, $\mathrm{n}(\%)$ & $8(15.7)$ \\
\hline
\end{tabular}

$S D$, Standard deviation.

Three patients have been reoperated to replace the aortic valve. In all cases, the cause was infection: 2 cases of valve endocarditis and 1 abscess of the mitro-aortic continuity. One of these 3 patients had a bicuspid valve. Freedom from reoperation on the aortic valve at 5 years was $96.8 \%$ $\pm 3.2 \%$ (Figure 2 ).

Freedom from recurrent aortic insufficiency greater than $2+$ at 5 years was $96.8 \% \pm 3.2 \%$ (Figure 2). In particular, at the echocardiographic assessment during the follow-up, 42 patients $(82 \%)$ presented with aortic insufficiency grade $0,6(12 \%)$ with grade $1+, 1(2 \%)$ with grade $2+$, and 2 $(4 \%)$ with grade $3+$ (Figure 3 ). When the gradients across the aortic valve were considered, we observed an average maximum gradient of $15.2 \pm 3.2 \mathrm{~mm} \mathrm{Hg}$ and an average mean gradient of $8.6 \pm 2.4 \mathrm{~mm} \mathrm{Hg}$. In the 3 patients who underwent reoperation on the aortic valve, we observed increased transvalvular gradients (maximum, $38.6 \pm 9.4$

TABLE 2. Preoperative echocardiographic characteristics $(\mathbf{n}=\mathbf{5 1})$

\begin{tabular}{lc}
\hline \multicolumn{1}{c}{ Characteristic } & Preoperative value \\
\hline Annulus, $\mathrm{mm} \pm \mathrm{SD}$ & $25.5 \pm 1.5$ \\
Sinuses of Valsalva, $\mathrm{mm} \pm \mathrm{SD}$ & $48.1 \pm 5.4$ \\
Sino-tubular junction, $\mathrm{mm} \pm \mathrm{SD}$ & $48.5 \pm 6.6$ \\
Ascending aorta, $\mathrm{mm} \pm \mathrm{SD}$ & $51.9 \pm 5.4$ \\
Aortic insufficiency: cause, $\mathrm{n}(\%)$ & \\
$1 \mathrm{~b}$ & $46(90.2)$ \\
$1 \mathrm{~b}+2$ & $2(3.9)$ \\
$1 \mathrm{~b}+3$ & $3(5.9)$ \\
Aortic insufficiency: grading, $\mathrm{n}(\%)$ & \\
$1+$ & $12(23.5)$ \\
$2+$ & $23(45.1)$ \\
$3+$ & $7(13.7)$ \\
$4+$ & $9(17.6)$ \\
\hline
\end{tabular}

$S D$, Standard deviation.

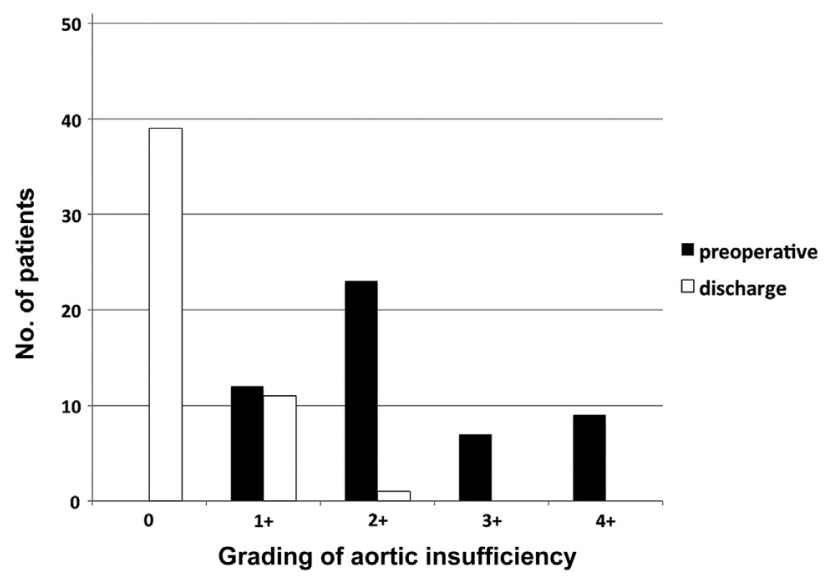

FIGURE 1. Variation in aortic insufficiency grading at discharge.

$\mathrm{mm} \mathrm{Hg}$; mean, $24.9 \pm 7.2 \mathrm{~mm} \mathrm{Hg}$ ) with concomitant aortic insufficiency in only 2 patients.

\section{Subgroup Analysis: Tricuspid Versus Bicuspid Valves}

When patients were stratified according to the morphology of the aortic valve, we did not record any difference in terms of freedom from time-related events at follow-up between tricuspid and bicuspid valves.

In particular, survival at 5 years was $91.7 \% \pm 4.7 \%$ versus $88.9 \% \pm 10.5 \%(P=.69)$, freedom from reoperation was $96.4 \% \pm 3.5 \%$ versus $100 \%(P=.29)$, and freedom from aortic insufficiency greater than $2+$ was $96.4 \% \pm 3.5 \%$ versus $100 \%(P=.62)$.

\section{COMMENT}

Until 1992, the technique described by Bentall, with its subsequent modifications, represented the gold standard for the treatment of aortic root aneurysms involving a diseased aortic valve. However, the replacement of the aortic root with a composite conduit brings with it all the complications related to any valvular prosthesis (bleeding/ hemorrhage as a consequence of anticoagulation, thrombosis, endocarditis, structural valve deterioration).

Therefore, since the first reports of David and Feindel ${ }^{1}$ and Sarsam and Yacoub, ${ }^{2}$ the techniques that spare the aortic valve have gained widespread diffusion for cases of aortic root aneurysm and aortic valve regurgitation.

Our study analyzes the midterm results of a valve-sparing aortic root procedure using the reimplantation technique; in every case, a straight tubular graft was used throughout the study period.

TABLE 3. Number of patients classified according to quartiles of follow-up length

\begin{tabular}{lcccc}
\hline Quartile of follow-up (y) & $>1$ & $1-4$ & $5-7$ & $8-10$ \\
Number of patients & 13 & 12 & 13 & 13 \\
\hline
\end{tabular}



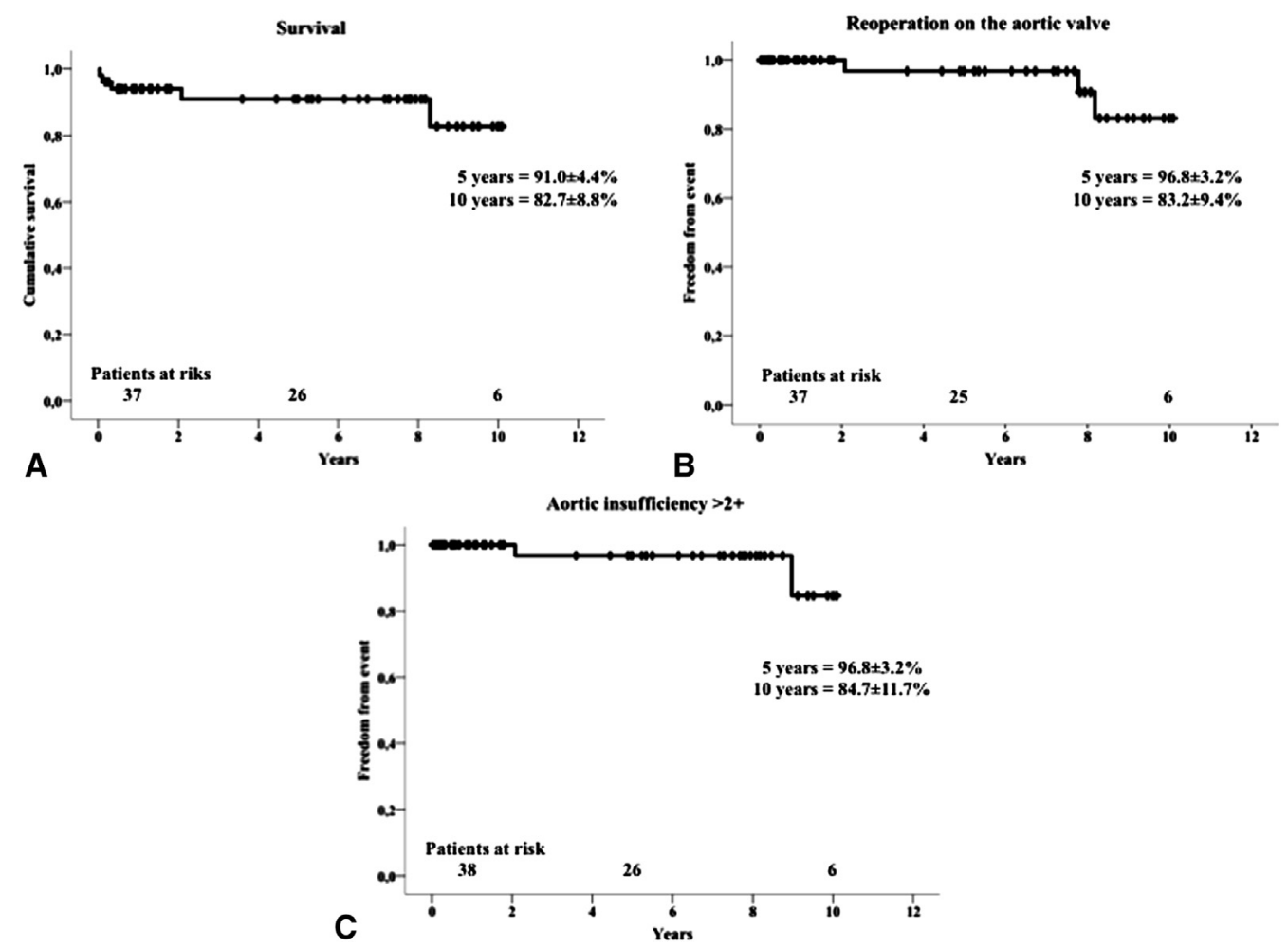

FIGURE 2. Freedom from time-related events. A, Survival. B, Freedom from reoperation on the aortic valve. C, Freedom from recurrent aortic insufficiency greater than $2+$.

Although the procedures to spare the aortic valve represent a technical challenge reserved only for experienced hands, most reports describe in-hospital mortality of between $0 \%$ and $4 \%$, either for David I or neosinuscreating techniques. ${ }^{14-16}$ In the present series, in-hospital mortality was $0 \%$, confirming that the reimplantation procedure may be considered a benchmark for the treatment of patients with dilated functional aortic annulus.

However, all the patients included in the study were operated electively, and patients with acute aortic dissection were not considered because this peculiar subset of patients has higher early mortality, related more to the underlying pathology than to the aortic procedure itself. ${ }^{3,15,16}$

When the degree of aortic insufficiency at discharge was considered, a significant increase in valve competence could be observed postoperatively. In an in vitro study on the Valsalva graft, Maselli and colleagues ${ }^{17}$ demonstrated that a 1:1 ratio between the base and the sino-tubular junction is ideal to restore adequate valve competence after the reimplantation technique. These findings, however, are also appropriate for a straight tube that, by definition, has the same diameter along all its length, both proximally at the ventriculo-aortic junction and at the level where the commissures are reimplanted (the new sino-tubular junction).

Our patients presented more frequently with dilated sinotubular junction and sinuses and a rather normal basal ring. Our institutional policy is to treat the aortic root pathology by addressing all the components of the functional aortic annulus to prevent further dilatation that might compromise the late results of the procedure. ${ }^{18}$ This kind of approach, however, may raise criticism because it may seem to be a more liberal indication of the David procedure in cases when other techniques have been proved to be equally valid options. ${ }^{19}$

The high incidence of only mild aortic insufficiency at the time of surgery may also raise concern. However, an earlier indication for surgery may help to avoid the negative

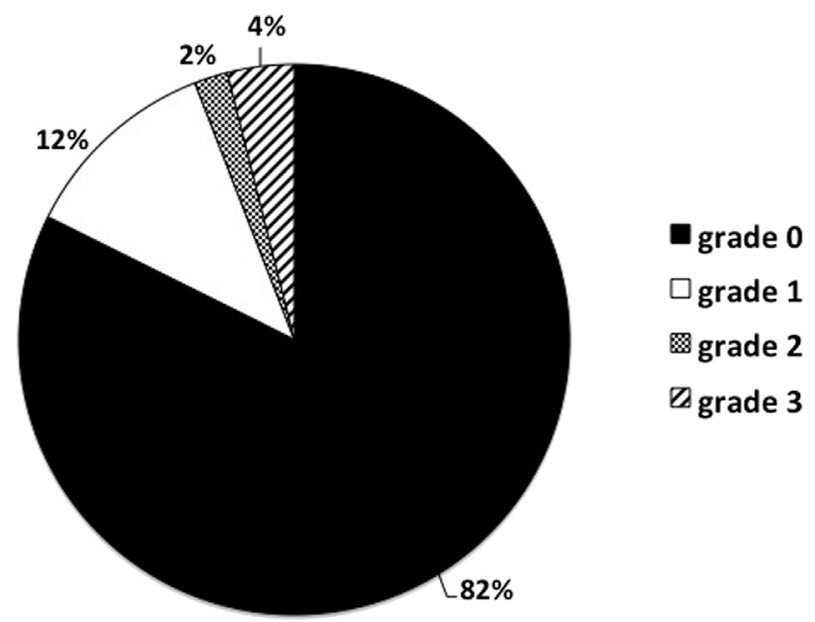

FIGURE 3. Different degrees of aortic insufficiency at last echocardiographic follow-up. 
remodeling effect of chronic regurgitation on the aortic cusps. ${ }^{20}$

This literature background prompted us to develop a strict selection protocol, mainly based on a careful intraoperative inspection and evaluation of the quality of the cusps, both before and after the reimplantation, to ensure a long-lasting repair. ${ }^{8}$ Accordingly, already remodeled cusps requiring the adjunct of further repairs were not considered suitable to be spared, ${ }^{21-24}$ This is usually the case in older patients with less elastic cusps ${ }^{8}$ who were therefore considered not suitable for a valve-sparing procedure.

The valve-sparing procedures are appealing in the longterm for excellent survival, ${ }^{3,16}$ increased freedom from redo operation on the aortic valve,,$^{3,15,16,25}$ and improved quality of life, mainly related to the avoidance of prosthesis-related complications (eg, thrombosis and the need for anticoagulation).

However, the reports in the literature fail to demonstrate a clear superiority of David I over neosinus-creating techniques (eg, Valsalva graft or David V Stanford modification), ${ }^{26}$ Accordingly, the substantial differences observed also between the various neosinuses techniques might reflect more the results of the underlying cusp pathology than valve reimplantation technique.

The development of endocarditis is generally low because the presence of native tissue should be protective against infection. ${ }^{15,27}$

In our cohort, the incidence of endocarditis was $1.23 \%$ patients per year, and this was the only indication for reoperative surgery.

There is general agreement that the presence of sinuses reduces the stress on the leaflets and increases the freedom from the deterioration induced by the opening and closing cycles. ${ }^{5,28}$ Thus, the altered dynamic of the aortic valve reimplanted inside a straight cylindrical tube could promote structural deterioration, exposing the patient to the risk of endocarditis. ${ }^{28,29}$ However, the echocardiographic controls allowed us to exclude any degeneration of the leaflets. Therefore, our results support those of Shresta and colleagues ${ }^{15}$ showing that the use of a straight tube does not have a negative effect on valvular function and anatomy. The dynamic function of the aortic valve has been investigated recently by D'Ancona and colleagues, ${ }^{30}$ who demonstrated the preserved elasticity of the aortic unit after the David I procedure under physical stress, without any increase in transvalvular gradients.

Similarly, when patients with a follow-up over the median were called back for further controls specifically designed to evaluate valve morphology and function, we did not observe either valve degeneration or impaired leaflet movements at 128 -slice CTA. It was interesting to see how the running sutures used to reimplant the valve recreated a sinuslike portion along the straight tube (Figure 4). In addition, our hypothesis of clinical reliability of the original reimplantation procedure is confirmed up to 20 years of follow-up. ${ }^{8}$

To the best of our knowledge, no study compares the incidence of endocarditis with the different modifications of the reimplantation technique. Accordingly, the superiority of one technique over the others has not been demonstrated, and further studies specifically designed to address this issue would certainly be welcome.

The risk of recurrent regurgitation is certainly an intrinsic limitation of any repair technique. ${ }^{31}$ However, many studies demonstrate freedom from recurrent aortic regurgitation after any kind of reimplantation procedure between $90 \%$ and $94 \%$ at 5 years. ${ }^{3,16}$ Leontyev and colleagues ${ }^{16}$ reported a slight trend of increasing aortic insufficiency grading in patients undergoing the David I procedure but they failed to demonstrate that the technique of reimplantation was a predictor of recurrent aortic regurgitation at midterm follow-up. Furthermore, David and colleagues ${ }^{27}$ showed that creation of neo-aortic sinuses had no effect on the recurrence of late aortic insufficiency at 10 years.

When our population of patients was divided according to the morphology of the aortic valve, we could not find any difference in major outcomes at follow-up, confirming the results of previously published series. ${ }^{32,33}$ According to our institutional policy, we are more aggressive on the aortic root in the case of root dilation and a bicuspid valve, following the cut-off of 1.4 suggested by Roman
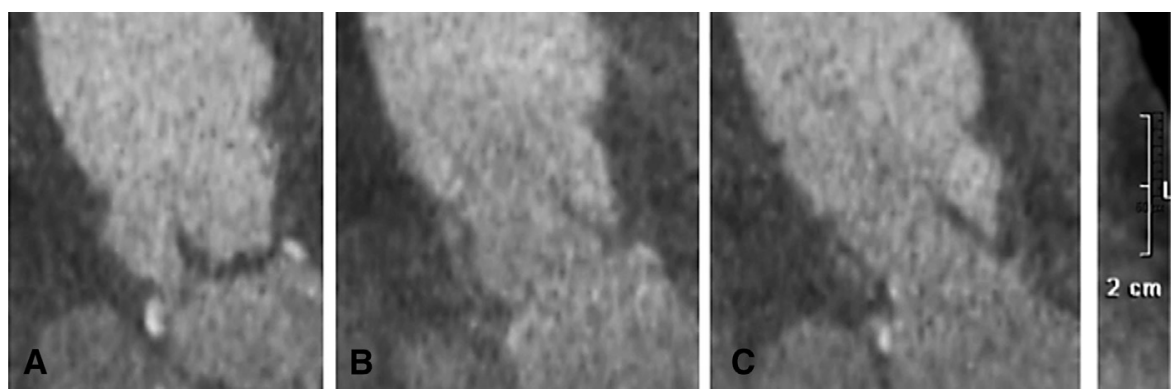

FIGURE 4. A 128-slice CTA scan of the aortic box showing preserved valve motion after the David I procedure during the various phases of the cardiac cycle. A, End diastole; B, early systole; C, complete opening at late systole. Note also the recreation of sinuslike portions made by the running sutures used to reimplant the valve. 
and colleagues. ${ }^{34}$ Furthermore, we agree with de Kerchove and colleagues ${ }^{35}$ that reimplantation is the best method to stabilize the repair of a bicuspid aortic valve in a dilated functional aortic annulus. However, our experience with the reimplantation of bicuspid valves is limited to 9 patients and larger series would be necessary to confirm our results.

\section{Limitations of the Study}

The main limitation of the study is related to the relatively small sample size of patients enrolled in the study. This is because the David procedure is usually reserved for a few experienced surgeons at a single institution. On the other hand, the single-center design of the study guarantees uniformity of the surgical technique and perioperative care. The $100 \%$ follow-up is also a strength.

Furthermore, in an attempt to validate our results in the surgical community, another major limitation is the lack of a control group of patients undergoing reimplantation with recreation of neosinuses. However, to fill this gap, we have tried to discuss our results in comparison with other studies reporting midterm follow-up outcomes of neosinuscreating techniques. In addition, our group is involved in an investigational trial aiming to evaluate the hemodynamic performance of 2 type of reimplantation procedure (straight tube vs Valsalva graft) with a propensity-matched cohort from Professor De Paulis.

More refined imaging tools, such as magnetic resonance imaging or dynamic computed tomography, as well as engineering models to evaluate finite element analytical data or velocity vector data from the aortic box, would certainly be useful to assess the degree of valve degeneration under different kinds of valve-sparing surgery.

The lack of substantial long-term follow-up details is another limitation of our study. More studies on this topic and case-control retrospective studies on larger series of patients may further clarify the role of graft geometry on the function of the aortic valve in the long term.

\section{CONCLUSIONS}

The reimplantation technique using a straight tubular graft is still a valid method for treating patients with aortic root aneurysms and normal or only minimally remodeled aortic cusps. The procedure can be performed safely with low in-hospital mortality and good results at midterm follow-up. Earlier referral to surgery and more radical treatment might achieve better results in patients with aortic root aneurysms with evidence of progressive dilation in the presence of a normal echocardiographic anatomy of the aortic cusps.

We sincerely thank Professor Massimo R. Costanzo for statistical support and Dr Valeria Garretto for the radiological investigations.

\section{References}

1. David TE, Feindel CM. An aortic valve-sparing operation for patients with aortic incompetence and aneurysm of the ascending aorta. J Thorac Cardiovasc Surg. 1992; 103:617-22.

2. Sarsam LAJ, Yacoub M. Remodeling of the aortic valve annulus. J Thorac Cardiovasc Surg. 1993;105:435-8.

3. David TE, Armstrong S, Ivanov J, Feindel CM, Omran A, Webb G. Results of aortic valve-sparing operations. J Thorac Cardiovasc Surg. 2001;122:39-46.

4. Bellhouse BJ. The fluid mechanics of the aortic valve. In: Ionescu ML, Ross DN, Woller GH, eds. Biological Tissue in Heart Valve Replacement. London: Butterworth-Heinemann; 1972:23-47.

5. Thubrikar MJ, Nolan SP, Aouad J, Deck JD. Stress sharing between the sinus and leaflets of canine aortic valve. Ann Thorac Surg. 1986;42:434-40.

6. Miller DC. Valve-sparing aortic root replacement in patients with Marfan syndrome. J Thorac Cardiovasc Surg. 2003;125:773-8.

7. De Paulis R, De Matteis GM, Nardi P, Scaffa R, Colella DF, Chiarello L. A new aortic Dacron conduit for surgical treatment of aortic root pathology. Ital Heart J. 2000;1:457-63.

8. David TE. Aortic valve sparing operations: outcomes at 20 years. Ann Cardiothorac Surg. 2013;2:24-9.

9. Boodhwani M, de Kerchove M, Glineur D, Poncelet A, Rubay J, Astarci P, et al Repair-oriented classification of aortic insufficiency: impact on surgical techniques and clinical outcomes. J Thorac Cardiovasc Surg. 2009;137:286-94.

10. Sievers HH, Schmidtke C. A classification system for the bicuspid aortic valve from 304 surgical specimens. J Thorac Cardiovasc Surg. 2007;133:1226-33.

11. Boodhwani M, de Kerchove L, Glineur D, Rubay J, Vanoverschelde JL, Noirhomme P, et al. Repair of regurgitant bicuspid aortic valves: a systematic approach. J Thorac Cardiovasc Surg. 2010;140:276-84.

12. El Khoury G, de Kerchove L. Principles of aortic valve repair. J Thorac Cardiovasc Surg. 2013;145:26-9.

13. Van Dyck M, Glineur D, de Kerchove L, El Khoury G. Complications after aortic valve repair and valve-sparing procedures. Ann Cardiothorac Surg. 2013;2: 130-9.

14. Erasmi AW, Sievers HH, Bechtel JFM, Hanke T, Stierle H, Misfeld M. Remodeling or reimplantation for valve-sparing aortic root surgery? Ann Thorac Surg. 2007;83:752-6.

15. Shrestha M, Baraki H, Maeding I, Fitzner S, Sarikouch S, Khaladj N, et al. Longterm results after aortic valve-sparing operation (David I). Eur J Cardiothorac Surg. 2012;41:56-62.

16. Leontyev S, Trommer C, Subramanian S, Lehmann S, Dmitrieva Y, Misfeld M et al. The outcome after aortic valve-sparing (David) operation in 179 patients: a single-centre experience. Eur J Cardiothorac Surg. 2012;42:261-7.

17. Maselli D, De Paulis R, Scaffa R, Weltert L, Bellisario A, Salica A, et al. Sinotubular junction size affects aortic root geometry and aortic valve function in the aortic valve reimplantation procedure: an in vitro study using the Valsalva graft. Ann Thorac Surg. 2007;84:1214-8.

18. Grande-Allen KJ, Cochran RP, Reinhall PG, Kunzelman KS. Mechanisms of aortic valve incompetence: finite-element modeling of Marfan syndrome. $J$ Thorac Cardiovasc Surg. 2001;122:946-54.

19. Albes JM, Stock UA, Hartrumpf M. Restitution of the aortic valve: what is new, what is proven, and what is obsolete? Ann Thorac Surg. 2005;80:1540-9.

20. Thubrikar MJ, Labrosse MR, Zehr KJ, Robicsek F, Gong GG, Fowler BL. Aortic root dilatation may alter the dimensions of the valve leaflets. Eur J Cardiothorac Surg. 2005;28:850-6.

21. Oka T, Okita Y, Matsumori M, Okada K, Minami H, Munakata H, et al. Aortic regurgitation after valve-sparing aortic root replacement: modes of failure. Ann Thorac Surg. 2011;92:1639-44.

22. De Paulis R, Scaffa R, Nardella S, Maselli D, Weltert L, Bertoldo F, et al. Use of the Valsalva graft and long-term follow-up. J Thorac Cardiovasc Surg. 2010;140: S23-7.

23. Settepani F, Bergonzini M, Barbone A, Citterio E, Basciu A, Ornaghi D, et al Reimplantation valve-sparing aortic root replacement with the Valsalva graft: what have we learnt after 100 cases? Interact Cardiovasc Thorac Surg. 2009;9: 113-6.

24. Hanke T, Charitos EI, Stierle U, Robinson D, Gorski A, Sievers HH, et al. Factors associated with the development of aortic valve regurgitation over time after two different techniques of valve-sparing aortic root surgery. J Thorac Cardiovasc Surg. 2009;137:314-9.

25. Kallenbach K, Hagl C, Walles T, Leyh RG, Pethig K, Haverich A, et al. Results of valve-sparing aortic root reconstruction in 158 consecutive patients. Ann Thorac Surg. 2002;74:2026-33. 
26. Kvitting JP, Kari FA, Fischbein MP, Liang DH, Beraud AS, Stephens EH, et al. David valve-sparing aortic root replacement: equivalent mid-term outcome for different valve types with or without connective tissue disorder. J Thorac Cardiovasc Surg. 2013;145:117-26.

27. David TE, Feindel CM, Webb GD, Colman JM, Armstrong S, Maganti M. Longterm results of aortic valve-sparing operations for aortic root aneurysm. J Thorac Cardiovasc Surg. 2006;132:347-54.

28. Grande-Allen KJ, Cochran RP, Reinhall PG, Kunzelman KS. Re-creation of sinuses is important for sparing the aortic valve: a finite element study. $J$ Thorac Cardiovasc Surg. 2000;119:753-63.

29. Erasmi A, Sievers HH, Scharfschwerdt M, Eckel T, Misfeld M. In vitro hydrodynamics, cusp-bending deformation, and root distensibility for different types of aortic valve-sparing operations: remodeling, sinus prosthesis, and reimplantation. J Thorac Cardiovasc Surg. 2005;130:1044-9.

30. D’Ancona G, Ciofalo R, Biondo D, Follis M, Follis F. Midterm follow-up dynamic echocardiography evaluation after ascending aorta replacement and reimplantation of the aortic valve (David operation) in a matched control study. Eur J Cardiothorac Surg. 2012;41:785-8.
31. Giebels C, Aicher D, Kunihara T, Rodionycheva S, Schmied W, Schäfers HJ. Causes and management of aortic valve regurgitation after aortic valve reimplantation. J Thorac Cardiovasc Surg. 2013;145: 774-80.

32. Badiu CC, Eichinger W, Bleiziffer S, Hermes G, Hettich I, Krane M, et al. Should root replacement with aortic valve-sparing be offered to patients with bicuspid valves or severe aortic regurgitation? Eur J Cardiothorac Surg. 2010; 38:515-22.

33. Aicher D, Langer F, Kissinger A, Lausberg H, Fries R, Schäfers HJ. Valvesparing aortic root replacement in bicuspid aortic valves: a reasonable option? J Thorac Cardiovasc Surg. 2004;128:662-8.

34. Roman MJ, Devereux RB, Kramer-Fox R, O'Loughlin J. Two-dimensional echocardiographic aortic root dimensions in normal children and adults. Am J Cardiol. 1989;64:507-12.

35. de Kerchove L, Boodhwani M, Glineur D, Van Dyck M, Vanoverschelde JL, Noirhomme P, et al. Valve sparing-root replacement with the reimplantation technique to increase the durability of bicuspid aortic valve repair. $J$ Thorac Cardiovasc Surg. 2011;142:1430-8. 